\title{
Perdas fermentativas e composição bromatológica da entrecasca de palmito pupunha ensilada com aditivos químicos
}

\section{Patrick Schmidt ${ }^{1}$, Paulo Rossi Junior ${ }^{1}$, Luciandra Macedo de Toledo ${ }^{2}$, Luiz Gustavo Nussio ${ }^{3}$, Danila Santiago de Albuquerque ${ }^{4}$, Beatriz Meduri ${ }^{4}$}

\author{
1 Universidade Federal do Paraná. Rua dos Funcionários, 1540 - CEP: 80035-050 - Curitiba, PR. \\ 2 APTA - Instituto de Zootecnia de Nova Odessa, SP. \\ 3 USP/ESALQ, Piracicaba, SP. \\ ${ }^{4}$ Curso de Graduação em Agronomia/Unesp, Registro, SP
}

RESUMO - Objetivou-se avaliar o efeito da inclusão de aditivos químicos na ensilagem de resíduos (entrecasca) da produção de palmito pupunha (Bactris gasipaes, Kunth). Utilizaram-se silos experimentais (baldes de 20 litros) providos de aparatos para determinação gravimétrica de perdas por gases e efluentes. Os tratamentos aplicados foram: controle (sem aditivos); ureia (1\% da MV) e cal virgem (1\% da MV). Decorridos 70 dias de armazenagem, os silos foram pesados, abertos e amostrados. As perdas por efluentes e gases aumentaram com a aplicação de cal virgem na ensilagem. As perdas totais de MS foram de 15,1; 14,4 e 26,6\% nas silagens controle, ureia e cal, respectivamente. Em todas as silagens, houve redução no teor de FDN e elevação da fração FDA, o que indica desaparecimento da fração hemicelulose. A relação cálcio:fósforo aumentou substancialmente com a adição de cal virgem, de 4,1:1 na silagem controle para 15,6:1 na silagem com cal. O resíduo da extração do palmito pupunha pode ser classificado como alimento de média qualidade e alto teor de umidade. Os aditivos aplicados na ensilagem não são efetivos em reduzir as perdas fermentativas no processo de conservação.

Palavras-chave: cal virgem, efluente, gases, resíduos, ureia

\section{Fermentative losses and chemical composition of pupunha palm by-products ensiled with chemical additives}

\begin{abstract}
Feeding animals with agro-residues may reduce costs and environmental concerns. The agroindustrial wastes used as ruminant feeding are an alternative for ambient problems caused by it accumulation. This study aimed to evaluate chemical additives on the ensilage of residues of pupunha palm (Bactris gasipaes, Kunth) production. Experimental silos (20 L buckets) were used equipped with meters to determine gas and effluent DM losses. The experimental treatments were: control (no additives); urea (1\% - wet basis) and calcium oxide (1\% WB). After 70 days storage, the silos were weighed, opened and sampled. Effluent and gas DM losses increased with the application of calcium oxide at ensiling. Total DM losses were 15.1, 14.4 and $26.6 \%$ for the Control, Urea and Calcium oxide treatments, respectively. In all the treatments there was reduction in the NDF and increase in ADF increasing rates, that showed hemicellulose disappearance. The Ca:P ratio increased dramatically after calcium oxide addition, from 4.1:1 to 15.6:1. The residue from pupunha heart of palm extraction can be classified as a medium quality foodstuff with high moisture content. The additive applied at ensiling are not effective in reducing fermentative losses during the conservation process.
\end{abstract}

Key Words: calcium oxide, effluent, gases, residues, urea

\section{Introdução}

A utilização de resíduos agroindustriais é tradicional e crescente na alimentação de ruminantes como forma de compensar os custos dos grãos e volumosos suplementares (Lima, 2005).

A disponibilidade desses resíduos varia entre regiões e estações do ano, o que dificulta a padronização das dietas.
Além disso, para a maioria dos resíduos, o principal entrave à total utilização é o alto teor de umidade, que requer cuidados especiais na conservação do alimento e onera sobremaneira o custo de transporte até a fazenda. Dessa forma, a avaliação do valor nutricional do produto e as perdas inerentes ao processo de conservação deve ser relacionadas na avaliação do benefício econômico da utilização de determinado resíduo na alimentação animal. 
O estado de São Paulo é o maior produtor nacional de palmito pupunha (Bactris gasipaes Kunth), com cerca de 30 mil hectares da cultura (Bovi, 2000), sobretudo no Vale do Ribeira, onde atinge 20 milhões de plantas cultivadas (Schattan \& Kotona, 2004).

Avaliando a cultura da pupunha, Santos et al. (2004) observaram produções entre 54 e 82 toneladas de massa verde (MV)/ha de resíduos potencialmente aproveitáveis na alimentação de animais. Entre esses resíduos, destaca-se a entrecasca do palmito, que se concentra e gera problemas ambientais nas indústrias beneficiadoras, em virtude do grande volume produzido diariamente e do efluente gerado no processo de decomposição do material. Pereira et al. (2006) classificaram esse resíduo como fibroso, de médio valor nutritivo, com 61,6\% de FDN, 9,6\% de proteína bruta (PB), $74,2 \%$ de digestibilidade in vitro da matéria seca (DIVMS) e 10,6\% de matéria seca (MS), características de um bom volumoso. O baixo teor de matéria seca dificulta o transporte e a utilização de resíduos úmidos como esse e, na maioria dos casos, a ensilagem têm sido adotada como forma de armazenamento e conservação desses produtos na propriedade rural.

A utilização de aditivos no processo de ensilagem tem por objetivos alterar positivamente características fermentativas e/ou bromatológicas do produto final (Vilela, 1998). Embora a composição bromatológica da silagem de resíduos da produção de palmito pupunha com aditivos já tenha sido avaliada (Rodrigues Neto et al., 2001), as perdas fermentativas nessas silagens, exclusivas ou associadas a aditivos químicos, ainda não foram relatadas. Aditivos como óxido de cálcio (cal virgem) e ureia têm sido avaliados no processo de ensilagem como possíveis agentes hidrolíticos (Carvalho et al., 2006; Baliero Neto et al., 2007) visando reduzir o teor da fração fibrosa e elevar a digestibilidade de plantas forrageiras.

O objetivo neste estudo foi avaliar as perdas fermentativas e a composição bromatológica de silagens de resíduos de pupunha utilizando aditivos químicos.

\section{Material e Métodos}

O experimento foi realizado no Pólo Regional Vale do Ribeira da Agência Paulista de Tecnologia dos Agronegócios (APTA), e no Campus Experimental de Registro da Universidade Estadual Paulista "Julio de Mesquita Filho" (Unesp), em Registro, São Paulo, no período de setembro a novembro de 2006.

$\mathrm{Na}$ ensilagem foram utilizadas entrecascas frescas de palmito pupunha, provenientes de indústria beneficiadora de palmito, que foram moídas no momento da ensilagem, em triturador elétrico estacionário. As silagens foram elaboradas em silos experimentais (baldes) com capacidade para $20 \mathrm{~L}$, com tampas providas de válvula do tipo Bunsen, e aparato para determinação de perdas fermentativas, conforme descrito por Jobim et al. (2007), para avaliação das perdas por gases (\% da MS), das perdas por efluentes ( $\mathrm{kg} / \mathrm{t} \mathrm{MV}$ ) e da perda total de MS (\% da MS).

A aplicação dos aditivos foi realizada imediatamente antes da ensilagem, compondo uma silagem controle, sem aditivos; uma com ureia ( $1 \%$ da MV) e outra com óxido de cálcio (cal virgem micropulverizada, na proporção de $1 \%$ da MV). Para aplicação, os aditivos foram diluídos em água não-clorada, na proporção de 40 L/t MV. Na silagem controle, foi aplicada igual quantidade de água. Após a homogeneização dos aditivos, a forragem fresca foi amostrada para determinação do teor de MS e da composição bromatológica (Tabela 1 ).

A forragem foi compactada nos silos por pisoteamento, buscando-se atingir massa específica de $600 \mathrm{~kg} / \mathrm{m}^{3}$. Em seguida, os silos foram pesados e lacrados com fita adesiva. Após 70 dias de armazenamento, os silos foram novamente pesados e abertos, usando-se as diferenças gravimétricas para determinação das perdas por efluentes e gases e da perda total de MS, segundo metodologia descrita por Jobim et al. (2007). A silagem foi retirada dos silos, homogeneizada e amostrada para determinações bromatológicas após secagem a $55{ }^{\circ} \mathrm{C}$ em estufa de

Tabela 1 - Composição bromatológica das entrecascas de pupunha frescas utilizadas na ensilagem

\begin{tabular}{|c|c|c|c|c|}
\hline \multirow[b]{2}{*}{ Variável } & \multirow[b]{2}{*}{ Controle, sem aditivos } & \multicolumn{2}{|c|}{ Silagem } & \multirow[b]{2}{*}{ Média } \\
\hline & & Ureia (1\% da MV) & Cal (1\% da MV) & \\
\hline Matéria seca, \% & 15,7 & 15,8 & 16,9 & 16,1 \\
\hline Proteína bruta, \% MS & 4,8 & 20,2 & 4,5 & 9,8 \\
\hline Fibra em detergente neutro, \% MS & 73,4 & 72,9 & 66,7 & 71,0 \\
\hline Fibra em detergente ácido, \% MS & 45,0 & 46,7 & 45,9 & 45,9 \\
\hline Hemicelulose, \% MS & 28,4 & 26,2 & 20,8 & 25,1 \\
\hline Cinzas, \% MS & 3,4 & 3,4 & 7,9 & 4,9 \\
\hline Cálcio, \% MS & 0,31 & 0,39 & 2,18 & 0,96 \\
\hline Fósforo, \% MS & 0,19 & 0,22 & 0,20 & 0,20 \\
\hline
\end{tabular}


ventilação forçada (Silva, 1981). Outra amostra foi congelada para posterior determinação de $\mathrm{pH}$ do extrato aquoso (Kung Jr. et al., 1984) utilizando-se potenciômetro digital.

As análises bromatológicas do material fresco e das silagens foram realizadas no Laboratório de Nutrição Animal do Departamento de Zootecnia da Universidade Federal do Paraná, em Curitiba, Paraná. As amostras foram moídas a 1 mm em moinho tipo Wiley para determinação dos teores de MS e cinzas (AOAC, 1990); PB pelo método micro Kjeldahl (AOAC, 1990); fibra insolúvel em detergente neutro (FDN) e fibra insolúvel em detergente ácido (FDA), pelo método sequencial usando-se ANKOM Fiber Analyzer (Holden, 1999). O teor de hemicelulose foi calculado pela diferença entre os teores de FDN e FDA.

O delineamento experimental usado foi inteiramente casualizado, com quatro repetições, considerando cada silo experimental uma unidade experimental. A análise de variância dos dados foi realizada usando-se o programa estatístico SAS ${ }^{\circledR}$, versão 6.12 para Windows ${ }^{\circledR}($ SAS, 1996), e as médias de perdas fermentativas e a composição bromatológica das silagens foram comparadas pelo teste Tukey.

\section{Resultados e Discussão}

O tratamento do resíduo de pupunha com ureia ou cal virgem não foi efetivo em reduzir as perdas fermentativas durante a ensilagem (Tabela 2). A produção de efluentes da silagem aditivada com cal virgem aumentou significativamente (152\%) em relação à silagem controle. A adição de ureia elevou de forma moderada (23\%) e não-significativa a produção de efluentes em relação à silagem controle. Embora as perdas por gases não tenham diferido da silagem controle ( $\mathrm{P}<0,05)$, a aplicação de cal virgem aumentou (51\%) e a de ureia reduziu (17\%) a produção de gases durante a ensilagem. Efeito semelhante foi observado para a perda total de MS, que elevou 11,5 unidades percentuais com a adição de cal virgem durante a ensilagem.

As perdas por gases representaram $71 \%$ da perda total de MS nas silagens controle (Tabela 2). Entretanto, nas silagens contendo aditivos, os gases representaram 62\% (ureia) e 61\% (cal) das perdas totais de MS. A elevação na perda de componentes solúveis pelos efluentes, em decorrência da aplicação dos aditivos químicos, provavelmente foi a causa desse resultado.

Não foram encontrados trabalhos na literatura com avaliação das perdas fermentativas em silagens de resíduos de pupunha. Da mesma forma, não há relatos sobre os efeitos da aplicação dos aditivos químicos usados neste estudo em silagens de resíduo de pupunha.

A entrecasca do palmito pupunha é um resíduo fibroso de alta umidade, com média de 14,3\% de MS (Tabela 1). Contudo, a capacidade de retenção de água parece ser alta nesse material, uma vez que a produção de efluentes na silagem controle foi relativamente pequena $(47,7 \mathrm{~kg} / \mathrm{t}) \mathrm{se}$ comparada à de outras forragens úmidas, como as gramíneas tropicais. Avaliando o efeito do tamanho de partículas sobre a produção de efluentes em silagens de capim-tanzânia colhido com 16,7\% de MS, Loures et al. (2005) verificaram produção média de 250 litros de efluente por tonelada de forragem ensilada. Da mesma forma, Bernardino et al. (2005) verificaram produções médias de $123 \mathrm{~L}$ de efluente por tonelada de capim-elefante ensilado com 12,4\% de MS.

A capacidade de retenção de água de uma forragem úmida pode estar relacionada ao teor de pectina desse alimento, conforme relatado em estudo sobre palma forrageira (Andrade et al., 2002), contudo, essa variável não foi avaliada neste experimento.

Embora a alta retenção de água seja um fator positivo no resíduo de pupunha ensilado, por reduzir as perdas por efluentes no processo e a necessidade de aditivos absorventes de umidade, o alto teor de umidade desse resíduo onera significativamente o custo final da unidade de MS, em decorrência principalmente das despesas com frete da forragem fresca e ensilada. Além disso, forragens muito úmidas são mais susceptíveis a fermentações indesejáveis, que podem comprometer a qualidade do produto final.

A aplicação da cal virgem na ensilagem acarretou elevação nas perdas por efluentes e gases em relação à silagem controle. Provavelmente esse efeito foi decorrente da ação hidrolítica do hidróxido de cálcio $\left(\mathrm{Ca}\left(\mathrm{OH}_{2}\right)\right)$, formado na reação entre o óxido de cálcio ( $\mathrm{CaO}$ - cal virgem) e a água.

Tabela 2 - Perdas fermentativas durante a ensilagem de entrecascas de pupunha

\begin{tabular}{lcccc}
\hline & \multicolumn{3}{c}{ Silagem } & \multicolumn{2}{c}{ CV } \\
\cline { 2 - 3 } Variável & Controle (sem aditivos) & Ureia (1\% da MV) & Cal (1\% da MV) & Média \\
\hline Efluentes, kg/t MV & $47,7 \mathrm{~b}$ & $58,8 \mathrm{~b}$ & $120,6 \mathrm{a}$ & 75,7 \\
Gases, \% MS & $10,8 \mathrm{ab}$ & $9,0 \mathrm{~b}$ & $16,3 \mathrm{a}$ & 25,6 \\
Perdas totais de MS, \% & $15,1 \mathrm{~b}$ & $14,4 \mathrm{~b}$ & $26,6 \mathrm{a}$ & 12,0 \\
\hline
\end{tabular}

Médias seguidas de letras diferentes, na linha, são estatisticamente diferentes $(\mathrm{P}<0,05)$ pelo teste Tukey. 
O hidróxido de cálcio possui ação hidrolítica comprovada (Berger et al., 1994) e promove ruptura da parede celular e liberação de conteúdo celular, o que pode ter acarretado elevação na produção de efluentes. Contudo, pesquisas desenvolvidas por Santos (2007) com silagens de cana-deaçúcar aditivadas com cal virgem não comprovaram aumento na produção de efluentes (20,5 kg/t MV) em relação à silagem controle (31,3 kg/t MV). Segundo esse autor, o alto teor de açúcar presente na silagem de cana pode ter exercido ação higroscópica e reduzido a produção de efluentes nesse volumoso quando adicionado de cal virgem.

Nas três silagens avaliadas, o teor de matéria seca (11,2\% em média) reduziu em relação ao da forragem original (Tabela 3), o que é parcialmente explicado pelas perdas de MS (Tabela 2). Contudo, o aumento relativo nos teores de PB da forragem fresca em relação à silagem não foi tão marcante, o que indica degradação da fração proteica em magnitude semelhante à perda total de MS. Esse efeito pode ser comprovado pelos teores da fração mineral (cinzas) na forragem antes e após a ensilagem, que apresentaram aumento de 45, 24 e 19\%, para as silagens controle, com ureia e cal, respectivamente, em decorrência da perda de MS (Tabela 2). Esses valores foram bastante superiores ao valor médio de elevação relativa no teor de PB observado (11,2\%).

As silagens apresentaram $\mathrm{pH}$ ligeiramente acima da faixa ideal, entre 3,8 e 4,0, proposta por McDonald et al. (1991), possivelmente em virtude do alto teor de umidade, que reduz por diluição o poder de acidificação dos ácidos orgânicos produzidos no processo. $\mathrm{O}$ pH da silagem com cal foi superior aos das silagens controle e com ureia, o que pode estar relacionado ao maior poder de tamponamento de bases fracas, como o hidróxido de cálcio formado na reação do óxido de cálcio com a água.

O teor de PB observado na silagem controle $(4,6 \%)$ foi inferior aos valores de 8,5\%, relatado por Rodrigues Neto et al. (2001), e 9,6\%, relatado por Pereira et al. (2006), e indica variabilidade na composição de diferentes resíduos da produção de palmito pupunha.

Conforme esperado, a adição de ureia elevou em 374\% o teor de PB da silagem em relação à silagem controle. Embora níveis de adição em torno de 1\% da MV sejam recomendados para aplicação na ensilagem da cana-deaçúcar (Pedroso et al., 2007), essa dose de ureia foi excessiva na ensilagem do resíduo de pupunha, em virtude do baixo teor de MS desse material. Considerando os dados de Pedroso et al. (2007) e deste experimento, a aplicação de 1\% da MV de ureia representou 3,4 e 6,4\% da MS para as silagens de cana-de-açúcar e pupunha, respectivamente. Dessa forma, o teor de PB observado na silagem com ureia (21,8\%) foi bastante superior aos obtidos com a mesma dose na cana-de-açúcar (16,6\%). Por não terem promovido redução nas perdas fermentativas, os resultados da silagem com ureia sugerem que a dose utilizada foi excessiva e tecnicamente inviável, podendo inclusive acarretar intoxicação em animais (Huntington \& Archibeque, 1999).

O teor de FDN (em média 68,6\% da MS) das silagens não foi influenciado pelos aditivos testados, contudo as silagens apresentaram comportamento diferenciado quanto à variação no teor de FDN entre a forragem fresca e as silagens. Nas silagens controle e com ureia, houve redução no teor de FDN, em 6,8 e 7,8\%, respectivamente, enquanto na silagem com cal, o teor de FDN aumentou 5,1\%. McDonald et al. (1991) afirmaram que perdas de FDN durante a ensilagem podem ser relativamente altas e correspondem principalmente à solubilização da fração hemicelulose.

A possível explicação para esse efeito é a rápida atuação da cal virgem sobre a hemicelulose da FDN. Os dados indicam 7,6 unidades percentuais a menos no teor de hemicelulose do material fresco que recebeu cal virgem (Tabela 1) em relação ao material fresco sem aditivos (controle).

Tabela 3 - Composição químico-bromatológica das entrecascas de pupunha ensiladas com aditivos químicos

\begin{tabular}{|c|c|c|c|c|c|}
\hline Variável & \multicolumn{3}{|c|}{ Silagem } & Média & CV $(\%)$ \\
\hline $\mathrm{pH}$ & $4,0 \mathrm{~b}$ & $4,1 b$ & $4,4 a$ & 4,2 & 3,18 \\
\hline Proteína bruta, \% MS & $4,6 a$ & $21,8 b$ & $4,2 \mathrm{a}$ & 10,2 & 7,97 \\
\hline Fibra em detergente neutro, \% MS & 68,4 & 67,2 & 70,1 & 68,6 & 3,23 \\
\hline Fibra em detergente ácido, \% MS & $50,9 b$ & $49,8 c$ & $53,1 \mathrm{a}$ & 51,3 & 0,97 \\
\hline Cálcio, \% MS & $0,45 b$ & $0,43 \mathrm{~b}$ & $2,83 a$ & 1,24 & 24,9 \\
\hline Fósforo, \% MS & $0,11 b$ & $0,17 \mathrm{a}$ & $0,18 \mathrm{a}$ & 0,15 & 12,8 \\
\hline
\end{tabular}

Médias seguidas de letras de letras diferentes, na linha, são estatisticamente diferentes $(\mathrm{P}<0,05)$ pelo teste Tukey. 
A reação de hidrólise da hemicelulose, após a adição da cal à forragem, ocorreu de forma brusca, e foi acompanhada de mudanças na coloração do material e aquecimento da massa (variáveis não mensuradas) e redução no teor de hemicelulose da forragem fresca (Tabela 1). Dessa forma, foi evidenciado aumento relativo no teor de FDN nas silagens com cal, em decorrência das perdas de MS, pois o teor de FDN na forragem fresca foi menor que nas demais silagens (Tabela 1). Comportamento semelhante foi observado por Baliero Neto et al. (2007), que verificaram redução no teor de FDN, de 55,5 para 49,3\%, com a adição de $1 \%$ de cal virgem em amostras colhidas imediatamente antes da ensilagem.

O teor de FDA aumentou 13,1; 6,6 e 15,7\% após a ensilagem para as silagens controle e com ureia e cal, respectivamente. Esses resultados indicam que, na silagem com cal virgem, a fração hemicelulose foi preferencialmente hidrolisada, em relação aos componentes da FDA, e que a elevação no teor de FDA foi proporcional às perdas fermentativas no processo (Tabela 2).

Os teores dos componentes da parede celular observados neste experimento foram inferiores aos relatados por Rodrigues Neto et al. (2001), que observaram 75,2 e 61,0\% da MS para as frações FDN e FDA da silagem de resíduos da pupunha, respectivamente. Por outro lado, análises realizadas por Pereira et al. (2006) evidenciaram teores de $61,6 \%$ de FDN e $38,0 \%$ de FDA na entrecasca fresca da pupunha. A composição bromatológica desses resíduos apresentou grande variação, que deve ser considerada no balanceamento de rações contendo esses subprodutos.

A adição de cal virgem elevou em 4,4 unidades percentuais (88\%) o teor de cinzas na silagem em relação ao controle; o cálcio foi o principal responsável pelo aumento dessa fração, que variou de $0,55 \%$ da MS (controle) para 2,83\% da MS (cal). De acordo com análise apresentada por Oliveira et al. (2007), a cal virgem micropulverizada apresenta 94,1\% de CaO em sua composição, o que justifica a elevação nos teores de cálcio.

Ambas as silagens contendo aditivos químicos apresentaram teor de fósforo mais elevado que o da silagem controle e, para todas as silagens, houve redução no teor desse elemento em comparação ao material original (Tabelas 1 e 3). Uma possível explicação para esse efeito é a perda do elemento fósforo no efluente, fato que parece não ter ocorrido com o cálcio, que apresentou aumento em todas as silagens. Contudo, a composição do efluente não foi analisada nesta pesquisa.

O tratamento da silagem com cal virgem alterou a relação cálcio:fósforo da silagem, cujos valores foram de 4,1; 2,5 e
15,7:1 para as silagens controle e com ureia e cal, respectivamente. $\mathrm{O}$ excesso de cálcio na silagem com cal virgem pode ser prejudicial aos animais, principalmente se associado a alimentos ricos nesse elemento, como a polpa cítrica peletizada. Miller (1970) afirma que dietas ricas em cálcio reduzem a absorção de zinco, podendo levar a severas lesões na epiderme (paraqueratose). Dessa forma, o uso de cal virgem como aditivo na ensilagem deve ser avaliado com cautela.

\section{Conclusões}

Resíduos da extração de palmito pupunha são alimentos volumosos com concentração limitada de nutrientes e alto teor de umidade, o que deve ser considerado nas estimativas de custo desse alimento. Os aditivos aplicados na ensilagem dos resíduos de pupunha não foram efetivos em reduzir as perdas fermentativas no processo. O uso de cal virgem na ensilagem solubilizou parcialmente a fração hemicelulose, mas aumentou as perdas por efluentes e as perdas totais de MS, elevando o teor de FDN após a ensilagem.

\section{Referências}

ANDRADE, D.K.B.; FERREIRA, M.A.; VÉRAS, A.S.C. et al. Digestibilidade e absorção aparentes em vacas da raça holandesa alimentadas com palma forrageira (Opuntia ficus-indica Mill) em substituição à silagem de sorgo (Sorghum bicolor (L.) Moench). Revista Brasileira de Zootecnia, v.31, n.5, p.2088-2097, 2002.

ASSOCIATION OF OFFICIAL ANALYTICAL CHEMISTS - AOAC. Official methods of analysis. 15.ed. Arlington: AOAC, 1990. v.1, 1117p.

BALIERO NETO, G.; SIQUEIRA, G.R.; REIS, R.A. et al. Óxido de cálcio como aditivo na ensilagem da cana-de-açúcar. Revista Brasileira de Zootecnia, v.36, n.5, p.1231-1239, 2007.

BERGER, L.L.; FAHEY, G.C.; BOURQUIN, L.D. et al. Modification of forage after harvest. In: FAHEY, G.C (Ed.) Forage quality, evaluation and utyilization. Madison: ASA, CSS, SSS, 1994. p.922-966.

BERNARDINO, F.S.; GARCIA, R.; ROCHA, F.C. et al. Produção e caracteristicas do efluente e composição bromatologica da silagem de capim-elefante contendo diferentes niveis de casca de café. Revista Brasileira de Zootecnia, v.34, n.6, p.2185-2191, 2005 (supl.).

BOVI, M.L.A. O agronégócio palmito de pupunha. O Agronômico, v.52, n.1, p.10-12, 2000.

CARVALHO, C.G.P.; PIRES, A.J.V.; VELOSO, C.M. et al. Valor nutritivo do bagaço de cana-de-açúcar amonizado com quatro doses de uréia. Pesquisa Agropecuária Brasileira, v.41, n.1, p.125-132, 2006.

HOLDEN, L.A. Comparison of methods of in vitro dry matter digestibility for ten feeds. Journal of Dairy Science, v.82, n.8, p.1791-1794, 1999.

HUNTINGTON, G.B.; ARCHIBEQUE, S.L. [1999]. Pratical aspects of urea and ammonia metabolism in ruminants. Proceedings of American Society of Animal Sciences, 1999. 23p. Disponível em: <http://jas.fass.org/cgi/reprint/77/E-Suppl/1-x.pdf> Acesso em: 29/11/2007. 
JOBIM, C.C.; NUSSIO, L.G.; REIS, R.A. et al. Avanços metodológicos na avaliação da qualidade da forragem conservada. Revista Brasileira de Zootecnia, v.36, p.101-120, 2007 (supl. especial).

KUNG JR., L.; GRIEVE, D.B.; THOMAS, J.W. et al. Added ammonia or microbial inocula for fermentation and nitrogenous compounds of alfafa ensiled at various percents of dry matter. Journal of Dairy Science, v.67, p.299-306, 1984.

LIMA, M.L.M. Uso de subprodutos da agroindústria na alimentação de bovinos. In: REUNIÃO ANUAL DA SOCIEDADE BRASILEIRA DE ZOOTECNIA, 42., 2005, Goiânia. Anais... Goiânia: Sociedade Brasileira de Zootecnia, 2005. p.322-329.

LOURES, D.R.S.; NUSSIO, L.G.; PAZIANI, S.F. et al. Composição bromatológica e produção de efluente de silagens de capimtanzânia sob efeitos do emurchecimento, do tamanho de partícula e do uso de aditivos biológicos. Revista Brasileira de Zootecnia, v.34, n.3, p.726-735, 2005.

McDOnAld, P.; HENDERSON, A.R.; HERON, S.J.E. The biochemistry of silage. 2.ed. Marlow: Chalcombe Publications, 1991. 340p.

MILLER, W.J. Zinc nutrition of cattle: a review. Journal of Dairy Science, v.53, n.8, p.1123-1135, 1970.

OLIVEIRA, M.D.S.; ANDRADE, A.T.; BARBOSA, J.C. et al. Digestibilidade da cana-de-açúcar hidrolisada, in natura e ensilada para bovinos.Ciência Animal Brasileira, v.8, n.1, p.41-50, 2007.

PEDROSO, A.F.; NUSSIO, L.G.; LOURES, D.R.S. et al. Efeito do tratamento com aditivos químicos e inoculantes bacterianos nas perdas e na qualidade de silagens de cana-de-açúcar. Revista Brasileira de Zootecnia, v.36, n.3, p.558-564, 2007.

PEREIRA, L.G.R.; FERREIRA, A.L.; BARREIROS, D.C. et al. Composição bromatológica e cinética de fermentação ruminal in vitro da entrecasca e fruto da pupunha. In: REUNIÃO ANUAL DA SOCIEDADE BRASILEIRA DE ZOOTECNIA, 43., 2006, João Pessoa. Anais... João Pessoa: Sociedade Brasileira de Zootecnia, 2006. (CD-ROM).

RODRIGUES NETO, A.J.; BERGAMASCHINE, A.F.; ISEPON, O.J. et al. Efeito de aditivos no valor nutritivo de silagens feitas com subproduto da extração do palmito de pupunha (Bactris gasipaes H.B.K.). Revista Brasileira de Zootecnia, v.30, n.4, p.1367-1375, 2001.

SANTOS, R.A.; HERNANDEZ, F.B.T.; VICENTE, V.E.R. et al. Influências da irrigação localizada na produção de matéria verde de pupunheira (Bactris gasipaes HBK) utilizada na alimentação animal. In: CONGRESSO BRASILEIRO DE ENGENHARIA AGríCOlA, 33., 2004, São Pedro. Anais... São Pedro: Sociedade Brasileira de Engenharia Agrícola, 2004. (CD-ROM).

SANTOS, M.C. Aditivos químicos para o tratamento da canade-açúcar in natura e ensilada (Saccharum officinarum L.) 2007. 112f. Dissertação (Mestrado em Agronomia) - Escola Superior de Agricultura “Luiz de Queiroz”/Universidade de São Paulo, Piracicaba.

SCHATTAN, S.; KOTONA, A.P.L. Vale do Ribeira: O rei dos palmitos - uma solução ecológica. Informações Econômicas, v.34, n.9, p.45-46, 2004.

SILVA, D.J. Análise de alimentos: métodos químicos e biológicos. Viçosa, MG: Universidade Federal de Viçosa, 1981. 165p.

STATISTICAL ANALYSIS SYSTEM - SAS. SAS user's guide: Statistics. Cary: SAS Institute, 1996. 983p.

VILELA, D. Aditivos para silagem de plantas de clima tropical. In: REUNIÃO ANUAL DA SOCIEDADE BRASILEIRA DE ZOOTECNIA, 35., 1998, Botucatu. Anais... Botucatu: Sociedade Brasileira de Zootecnia, 1998. p.73-108. 